Int.J. Hum. Soc. Dev. Res.

ISSN (P):2521-1439; ISSN (E):2523-4331

Volume 1, Number 2, 2017. 28-34

DOI:10.30546/2523-4331.2017.1.2.28

\title{
SUSTAINABILITY IN BARBARA KINGSOLVER'S PRODIGAL SUMMER
}

\author{
Dlnya Abdalla MOHAMMED ALI \\ University of Sulaimani, Iraq
}

(C) The Author(s) 2017

\begin{abstract}
Sustainability is a concept used when referring to the various human actions embraced with the objective of ensuring the ability of the future generations to fulfi 1 their needs using the available natural resources. Literature works have also developed the ideology of sustainability through narratives and fictional novels. The Barbara Kingsolver's Prodigal Summer is one of such literary works that have featured sustainability and environmental conservation as the main themes in their plots. Kingsolver uses three interwoven chapters and three protagonists to develop the idea of sustainability in environmental, economic and social aspects. She demonstrates a complex mutual relationship between human beings and the natural wildlife resources. The author also uses the main characters characteristic of great passion for protecting the ecosystem to demonstrate the importance of maintaining an ecological balance for the sake of future generations. The novel description of the existing mutual relationship in the ecosystem also shows the dynamic forces in the environment that ensure the survivability of each constituent of the environment. Hence, human beings should envision in the concept of environmental protection to support sustainable lives for the future generations.
\end{abstract}

(C)2017.All rights reserved

\section{ARTICLE HISTORY}

Received: $18 / 02 / 2017$

Accepted: 09/07/2017

Published online: 05/10/2017

\section{KEYWORDS}

Sustainability, human actions, ecosystem, environment, ecological balance. 


\section{Introduction}

Sustainability is a concept commonly used to refer to the various human actions meant to utilise the available natural resources without compromising the capacitive potential of the forthcoming generations to satisfy their necessities (Madu \& Kuei 1). Sustainability comprises of different aspects including biodiversity, interdependence, ecosystem, personal, and social responsibility (Bebbington, Unerman \& O'Dwyer 4). Hence, sustainable growth becomes a common goal for all human beings on the planet. The awareness about the concept helps people to explore their mutual relationships with the earth's resources, wildlife, and other people. This profound connection to the natural environment has been demonstrated in Barbara Kingsolver's novel Prodigal Summer. The author uses the main protagonists of the story to show interdependence between the natural environment and its living inhabitants, as well as human beings and the relationship they have with the natural ecosystem. The novel expounds on the theme of sustainability by demonstrating the social responsibility of people to preserve the natural world from the threat of extinction that would risk the survival of future generations. It extends the sustainability literature regarding the natural environment, economic, and social aspects of the ideology.

Barbara Kingsolver's Prodigal Summer is comprised of three interwoven stories that are correlated through a complex network of relationships. The events of the story unfold in a small society living in Southern Appalachia, which doubles as the author's residence in both fiction and reality. Each of the stories revolves around one of the three main characters of the Prodigal Summer. For instance, the first chapter, - Predators, $\|$ features a female character named Deanna Wolfe, who is in her 40's age. She is a reclusive wildlife conservative agent and a biologist in an isolated mountain environment. She is also a predator lover overseeing a den of coyotes that had recently migrated to the region. The events of the second chapter revolve around Lusa Maluf Landowski, a moth lover, who lives several miles away from the mountain.

The female character originates from a small town and later happens to be a farmer's wife in the Southern Appalachian society thus making it her profession. Garnett is introduced in the third chapter of the book, -Old Chestnuts, $\|$ championing for the extinct American chestnut tree. 
During one of the humid summer seasons, as the natural urge for procreation engulfed the South Appalachian countryside, the three characters discover a complex network of relationships between each other. They also notice their mutual connection with the natural ecosystem environment they dwell in it. Further, the three characters discover their communal circles and social relationships embedded by intimacy, the realities of small-scale farming, and the biodiversity of the region. Through these sequential events, Kingsolver's Prodigal Summer demonstrates the theme of sustainability for the survivability of future generations.

\section{Sustainability Theme Points}

The first thematic presentation of sustainability takes place in the first chapter of the Kingsolver's Prodigal Summer. The author describes a vibrant mountain ecosystem comprising of wild animals and forest plants. Deanna is also described as an environmentalist who is a conservative wildlife agent in one of the outposts of the mountain. She had a great passion for conserving the wildlife and protecting the ecosystem from destruction by human economic activities. She chose to abandon the small city life to lead a solitude life in the forest and protect the wildlife from unscrupulous poachers. The love for biodiversity is an explicit indication and expression of the mutual relationship between human beings and the natural world. A disruption in the natural coexistence between small insects, animals, and plants can have severe implications for the planet and threaten the existence of some endangered species of flora and fauna. According to the findings from an ecological study by Naveh and Lieberman, the results and conclusions established the need to protect the environment to preserve the endangered species for the future generations (322). At the beginning of the novel's plot, a den of coyotes had just migrated to the Appalachian region following the favourable climatic conditions in the area that promoted the survivability of the animals. Deanna was determined to protect the natural world from the threat of destruction by human economic activities. For instance, she once met with a hunter, Eddie Bondo, carrying a gun for killing the prey and they ended up in a fierce quarrel. Deanna says»I believe we're on National Forest land, inside of a game-protection area where there's no hunting» (Kingsolver 5). Deanna saw hunting as a great threat to the ecosystem to which she was entirely devoted to protecting out of her passion. All these events are used to advance the author's concept of sustainability 
for a better ecosystem balance and protection of certain species from extinction. Disruptions in the environmental dynamics due to ferocious human activities can significantly affect the survivability of some plant and animal species. Consequently, the futurity of a sustainable life of the human generation would be threatened as some of the natural resources become scarce.

Barbara Kingsolver's Prodigal Summer also extends the knowledge of sustainability in the second chapter of the literature that involves events around one Lusa Maluf Landowski. Lusa is used in illustrating how various farming practices can affect the environment and influence the survivability of future human generations. For instance, activities that can lead to the death of some insects may have adverse effects on human economic activities such as agriculture. According to Reichle, the rationale behind the argument is that killing the predators may result in uncontrollable populations of pests (125). The result of such actions would include lowered quality and productivity of agricultural farms due to massive destruction of plants by pests beyond human control. The increasing number of pests through prey-predator interactions (Edwards 173) may also propagate disease spread. Similarly, the second chapter of the Prodigal Summer revolves around farming practices that might be detrimental to the future sustainability of the environment and the entire human generation. Lusa utilises the organic methods of farming to maintain a balanced ecosystem and prevent deaths of the endangered species of living organisms from extinction. However, her neighbouring farmers practice an artificial control of pests by the use of pesticides. This is seen to have irritated Lusa to the point of disputing the neighbours and condemning spraying as a method of pest control. She explains the benefits of organic farming methods including a sustainable ecosystem for the future sustainability of the human race. For instance, Lusastates -Can you believe people spray insecticide all over their fields?\| she continues-Look at all the beautiful creatures that die. It's like dropping a bomb on a city just to get rid of a couple of bad guysll (Kingsolver 299). The author manages to express the concept of sustainability through these events by showing the risks associated with inorganic farming practices. Consequently, this may result in an imbalance in the ecosystem thus jeopardising the future of agriculture and economic sustainability of the future human generations.

Kingsolver's Prodigal Summer continues to expound on the issue of sustainability through its third chapter of the plot. In this chapter, Garnett, an old man, is presented as a character afflicted with the negative implications of some 
human activities. In essence, extinction of some species of plants and living organisms may have significant effects on the ecological balance of the planet. For example, the death of predatory animals due to pesticides may cause an uncontrolled breeding of the prey, and persistent re-nesting of the population to overcome the challenge (Edwards 311). The consequence of this is that the prey may compete for the available food in the natural environment eventually leading to its scarcity. Therefore, the survivability of the entire population of the animals may be threatened to the extent of their death and thus causing an ecological imbalance. According to Sommer, the continued renewal of natural resources by the ecosystem processes ensures food security and prevents organisms from starvation. On the other hand, extinction of some plants species and trees may lead to adverse effects on the environment. For instance, trees are a vital constituent of the environment for maintaining appropriate levels of carbon dioxide gas in the atmosphere. A reduction in the forest coverage may result in uncontrollable amounts of carbon dioxide from pollutants such as vehicle emissions to the atmosphere leading to global warming (Sterner 311). Kingsolver demonstrates this fact through Garnet's campaigns against the extinction of the Chestnut tree, quoted in the line - He was haunted by the ghosts of these old chestnuts, by the great emptiness their extinction had left in the worldll (Kingsolver 128). He is depicted as one who denounces the unregulated human activities leading to the reduction or destruction of the tree family. Kingsolver attempts to explain the threat to the sustainability of the future generations as trees and the size of forests gradually decrease. The situation could possibly lead to global warming and the related consequences such as a rise in the sea level.

\section{Conclusion}

In conclusion, it is apparent that sustainability is a goal to be achieved by the human race in anticipation of the social well-being of future generations. Sustainability features a broad spectrum of important constituents that people should consider in their efforts to promise better lives for the future generations. Such factors include the environmental, economic, and social aspects of the ecosystem. Typically,sustainable growth involves a set of environmental conservation and protection strategies to minimise the destruction caused by some of the human economic activities while at the same time enjoying the benefits of the natural environment. The measures are meant to ensure an optimal utilisation of the natural resources without undermining the ability of the forthcoming 
generations to lead stable lives. This mutual connection between people and the ecosystem hasbeen comprehensively demonstrated in Barbara Kingsolver's Prodigal Summer. The author manages to use three interrelated stories to present the different aspects of environmental sustainability. Kingsolver expressed the mutual love for conserving the natural environment through the main protagonists in the literature. In so doing, she illustrates the interdependence between plants, small insects, animals, as well as human beings for the survivability of each other. Further, she also shows the importance of protecting each element of the ecosystem to prevent the endangered species from extinction. Barbara Kingsolver, therefore, extends the knowledge of sustainability by using the novel to emphasise on the issue and ensure the protection of the ecological balance. These conservation practices are meant to make sure that the future human generations will adequately meet their needs using the available natural resources.

\section{Disclosure statement}

No potential conflict of interest was reported by the author.

\section{Contact Information}

E-mail: mariwan.hasan@univsul.edu.iq 


\section{References and notes:}

Baumgartner, Rupert J. (2009). Organizational culture and leadership: Preconditions for the development of a sustainable corporation. Sustainable Development, vol. 17, no. 2. pp. 102-113.

Bebbington, Jan, Jeffrey Unerman, and Brendan O`Dwyer, eds. (2014). Sustainability accounting and accountability. Routledge.

Edwards, C. A., ed. (2013). Environmental pollution by pesticides. Vol. 3. Springer Science \& Business Media.

Hargreaves, Andy, and Dean Fink. (2003). Sustaining leadership. Phi Delta Kappan, vol. 84, no. 9. pp. 693-700.

Kingsolver, Barbara. (2000). Prodigal summer. New York: HarperCollins. Print.

Laughlin, Aubrey A. (2016). Deconstructing exploitative systems and restoring a balanced biosphere: An ecofeminist posthumanist reading of Jane Smiley's -A Thousand Acres\| and Barbara Kingsolver's - Prodigal Summer.\|l ProQuest. search.proquest.com/openview/094764ca30cf4ddaf24f3ddda326aa88/1?pqorigsite $=$ gscholar \&cbl=18750\&diss=y. Accessed 30 Aug. 2017.

Lawhorne, Alison E. (2012 ). Everything we need is here: Restoring environmental bonds through activism in solar storms by Linda Hogan, Potiki by Patricia Grace, and Prodigal Summer by Barbara Kingsolver.l ProQuest. search.proquest.com/openview/b900b167fd 79e0f9eb6e30cddfcfaa3b/1?pqorigsite $=$ gscholar \&cbl=18750\&diss=y. Accessed 30 Aug. 2017.

Madu, Christian N., and Chu-hua Kuei, eds. (2012). Handbook of sustainability management.World Scientific.

Marshall, Judi. (2011). En-gendering notions of leadership for sustainability. Gender, Work \& Organization, vol. 18, no. 3. pp. 263-281.

Naveh, Zev, and Arthur S. Lieberman. (2013). Landscape ecology: Theory and application.Springer Science \& Business Media.

Pretty, Jules. (2008 ). Agricultural sustainability: Concepts, principles, and evidence. Philosophical Transactions of the Royal Society B: Biological Sciences, vol. 363, no. 1491. pp. 447-465.

Reichle, David E., ed. (2013). Analysis of temperate forest ecosystems. Vol. 1. Springer Science \& Business Media.

Sommer, Ulrich, ed. (2012). Plankton ecology: Succession in plankton communities. Springer Science \& Business Media.

Sterner, Thomas, ed. (2012). Economic policies for sustainable development. Vol. 7. Springer Science \& Business Media. 